\title{
Effects of botulinum toxin A on the sphincter of Oddi: an in vivo and in vitro study
}

\author{
J Sand, I Nordback, P Arvola, I Pörsti, A Kalloo, P Pasricha
}

\begin{abstract}
Background-Botulinum toxin $A$ is a potent inhibitor of the release of acetylcholine from nerve endings. Local injection of botulinum toxin has recently been suggested to be helpful in sphincter of Oddi dyskinesia by decreasing sphincter of Oddi pressure.

Aims-To explore the mechanism of action of botulinum toxin $A$ on sphincter of Oddi (SO) muscle.

Methods-Four piglets underwent duodenoscopy and SO manometry was performed. After obtaining a baseline pressure, the SO was injected with normal saline and the experiment repeated after one week. The SO was then injected endoscopically with botulinum toxin (40 U) with follow up manometry one week later. The sphincter of Oddi was removed from 10 pigs, cut into three rings, and placed in an organ bath. The force of contraction was measured and registered on a polygraph. Rings were stimulated by $70 \mathrm{~V}$ (10 $\mathrm{Hz}, 0.5 \mathrm{~ms}$ ) electrical field stimulation for 20 seconds, exogenous acetylcholine (100 $\mu \mathrm{M})$, and $\mathrm{KCl}(125 \mathrm{mM})$. Botulinum toxin $(0.1 \mathrm{U} / \mathrm{ml})$ or atropine $(1 \mu \mathrm{M})$ was added to the incubation medium and the stimulation was repeated.
\end{abstract}

Results-Mean basal SO pressure in the pigs remained unchanged after saline injection but decreased to about $50 \%$ of baseline value following botulinum toxin injection $(p=0.04)$. The contractions induced by direct stimulation of SO smooth muscle with $\mathrm{KCl}$ were not significantly affected by either atropine or botulinum toxin. In all rings exogenous acetylcholine induced contractions, which were totally blocked by atropine, but not by botulinum toxin. Electrical field stimulation induced contractions that were inhibited by both atropine and botulinum toxin.

Conclusion-Botulinum toxin inhibits pig sphincter of Oddi smooth muscle contractions by a presynaptic cholinergic mechanism, similar to that described in skeletal muscle.

(Gut 1998;42:507-510)

Keywords: sphincter of Oddi; botulinum toxin; pig; ex vivo

Botulinum toxin type A, a toxin produced by the bacterium Clostridium botulinum, is one of the most potent nerve poisons known to man. Botulinum toxin causes a flaccid paralysis of skeletal muscle by inhibiting the calcium dependent release of acetylcholine from nerve endings, ${ }^{1}$ an effect mediated by the enzymatic cleavage of the synaptic vesicle protein SNAP-25. ${ }^{2}$ In small doses injected locally, this property has been used in the treatment of spastic disorders of skeletal muscles. ${ }^{3}$ Recently, attention has focused on the effects of botulinum toxin on gastrointestinal smooth muscle, ${ }^{4}$ and its therapeutic applications. ${ }^{5}$ Thus botulinum toxin has been injected into the lower oesophageal sphincter for the treatment of achalasia, ${ }^{67}$ into the internal anal sphincter for patients with chronic anal fissures, ${ }^{8}$ and into the sphincter of Oddi (SO) of patients with upper abdominal pain and SO dysfunction. ${ }^{9} 10$ However, the physiological effects of botulinum toxin on SO smooth muscle has not been studied previously. The aim of this study therefore was to examine the effects of botulinum toxin on SO utilising a porcine model.

\section{Methods}

IN VIVO STUDIES

Piglets (Sus-scrofus domesticus, 20-30 kg) underwent sedation with intramuscular ketamine (400-500 mg) and intravenous pentobarbital (in an initial bolus of 130-195 mg). Respiration was provided via mechanical ventilation, with continuous monitoring of end expiratory $\mathrm{pCO}_{2}$. Intestinal intubation was accomplished by means of a standard adult duodenoscope (Olympus). Biliary manometry was performed in a station pull through fashion using a standard triple lumen SO manometry catheter (outer diameter $1.7 \mathrm{~mm}$ ), perfused with distilled water at a rate of $0.25 \mathrm{ml} / \mathrm{min}$ via a pneumohydraulic capillary infusion system (Arndorfer Medical Specialties Inc., Greendale, Wisconsin). Duodenal pressures were recorded simultaneously by means of a separate catheter taped to the outside of the endoscope. Pressures were recorded by a four channel polygraph (Dynograph Recorder R611, Beckman Instruments, Palo Alto, California). SO basal pressures were averaged from at least two pull throughs.

After measurement of basal SO pressures, normal saline (four aliquots of $0.25 \mathrm{ml}$ ) was injected into the SO using a sclerotherapy needle inserted through the endoscope. One week later, basal SO pressures were again measured. At this time, the SO of the animals was injected with botulinum toxin $(40 \mathrm{U} / \mathrm{ml}$ in aliquots of $0.25 \mathrm{ml}$ ) using a similar technique as before. After another week, basal SO pressure was again measured.

\section{EX VIVO STUDIES}

Ten pigs $(25-28 \mathrm{~kg})$ were used for this study. The animals were anaesthetised with controlled $1-2 \%$ efrane inhalation via tracheostomy, performed under ketamine $(10 \mathrm{mg} / \mathrm{kg}$, intra-
Finland.

Accepted for publication 31 October 1997 
Table 1 Effects of intrasphincteric botulinum toxin on basal SO pressures $(\mathrm{mm} \mathrm{Hg})$ in each of four individual animals

\begin{tabular}{lc}
\hline Baseline & After injection \\
\hline 15.5 & 10.5 \\
16.0 & 5.0 \\
8.0 & 4.5 \\
12.5 & 7.5 \\
\hline
\end{tabular}

muscularly) and thiopental $(10 \mathrm{mg} / \mathrm{kg}$ intravenously) induction. After laparotomy and duodenotomy, the entire SO was harvested and placed in an oxygenated physiological salt solution ( $\mathrm{pH} 7.4, \mathrm{NaCl} 119.0 \mathrm{mM}, \mathrm{NaHCO}_{3}$ $25.0 \mathrm{mM}$, glucose $11.1 \mathrm{mM}, \mathrm{CaCl}_{2} 1.6 \mathrm{mM}$, $\mathrm{KCl} 4.7 \mathrm{mM}, \mathrm{KH}_{2} \mathrm{PO}_{4} 1.2 \mathrm{mM}$, and $\mathrm{MgSO}_{4}$ $1.2 \mathrm{mM})$. The duodenal mucosa of the papilla was stripped away under a microscope, but the inner ampullary epithelium was left intact. The section beyond the SO was cut into three transverse sections (rings), each 1-2 mm thick. The rings were placed between two hooks in an organ bath chamber containing continuously oxygenated physiological salt solution at $37^{\circ} \mathrm{C}$. The force of the SO contraction was measured with an isometric force displacement transducer and registered on a polygraph (FTO3 transducer, Model 7E Polygraph; Grass Instrument Co., Quincy, Massachusetts).

After a stabilisation period of 30 minutes, the SO rings were stimulated by either $70 \mathrm{~V}(10$ $\mathrm{Hz}, 0.5 \mathrm{~ms}$ ) electrical field stimulation for 20 seconds, or $100 \mu \mathrm{M}$ exogenous acetylcholine

Table 2 Force of SO contractions after different stimulations

\begin{tabular}{lcccc}
\hline & \multicolumn{2}{l}{ Force of contraction $(\mathrm{mg})$} & \\
\cline { 3 - 4 } Type of stimulation & $N o$ & Control & Treatment & p Value \\
\hline $\begin{array}{l}\text { Potassium chloride } \\
\quad \text { Atropine }\end{array}$ & 8 & $2160(526)$ & $1770(393)$ & $>0.1$ \\
$\quad \begin{array}{l}\text { Botulinum toxin } \\
\text { Acetylcholine }\end{array}$ & 9 & $832(195)$ & $785(176)$ & $>0.1$ \\
$\quad \begin{array}{l}\text { Atropine } \\
\quad \text { Botulinum toxin }\end{array}$ & 9 & $461(141)$ & 0 & $<0.01$ \\
$\begin{array}{l}\text { Electrical field stimulation } \\
\quad \text { Atropine }\end{array}$ & 12 & $571(133)$ & $533(118)$ & $>0.1$ \\
$\quad$ Botulinum toxin & 5 & $918(830)$ & $27(27)$ & $<0.01$ \\
\hline
\end{tabular}

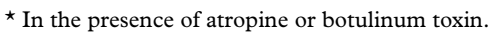

A
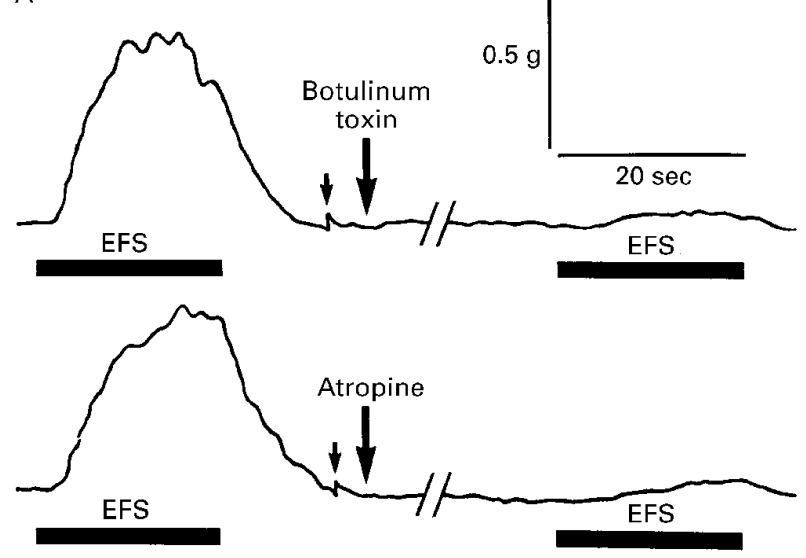

(acetylcholine chloride; Sigma Chemical Co., St Louis, Missouri). Potassium chloride (125 $\mathrm{mM}$ ), a potent direct smooth muscle stimulant, was used as positive control to test the viability of the preparation. After each stimulant the rings were rinsed twice with fresh incubation medium. Then $0.1 \mathrm{U} / \mathrm{ml}$ of botulinum toxin (Oculinum, Allergan Inc., Irvine, California) or $1 \mu \mathrm{M}$ of atropine (atropine sulphate; Sigma) was added to the medium, and the stimulation was repeated after 20 minutes of incubation. All results are expressed as mean (SEM), unless otherwise stated. Paired Student's $t$ test (with logistic transformation in skewed distributions) was used to calculate the significance of differences. The protocol was approved by the Animal Care Committee of the University of Tampere.

\section{Results}

IN VIVO EFFECTS

No evidence of adverse effects to botulinum toxin injection were apparent. Basal SO pressure (day 0) in the four pigs was 13.3 (4) $\mathrm{mm} \mathrm{Hg}$ (table 1). While no significant change occurred on day 7 after saline injection, basal SO pressure decreased by approximately $50 \%$ to $6.9(2.8) \mathrm{mmHg}$ after botulinum toxin injection $(\mathrm{p}=0.04)$.

\section{EX VIVO EFFECTS}

\section{Baseline stimulation}

$\mathrm{KCl}$, exogenous acetylcholine, and electrical field stimulation induced remarkable contractions in SO rings (table 2). Our preliminary experiments had shown that each of these three stimuli elicited reproducible contractions in pig SO rings. Thus, there was no significant shift in contractile force generation when the preparation was repeatedly (up to three times) challenged with the given stimuli (data not shown).

Effects of atropine and botulinum toxin on SO contractile response

Neither atropine nor botulinum toxin had any effect on the $\mathrm{KCl}$ induced contractions (table

Figure 1 (A) Representative tracings of sphincter of Oddi smooth muscle contractions induced by electrical field stimulation (EFS), and the effects of botulinum toxin and atropine. Small arrows indicate washes with fresh physiological salt solution. (B) Representative tracings of the sphincter of Oddi smooth muscle contractions induced by exogenous acetylcholine $(A C H)$, and the effects of botulinum toxin and atropine. Small arrows indicate washes with fresh physiological salt solution. 
2). On the other hand, both atropine and botulinum toxin seemed to inhibit electrically induced contractions (table 2, fig 1A). Atropine seemed to inhibit totally contractions induced by acetylcholine. However, contractions induced by acetylcholine were unaffected by botulinum toxin (table 2, fig 1B).

\section{Discussion}

The effects of botulinum toxin have been extensively studied in skeletal muscle systems. ${ }^{1}$ However, its effects on gastrointestinal smooth muscle, first described many decades ago, ${ }^{11-13}$ have only recently received attention. Pasricha et al showed for the first time that local injection of botulinum toxin inhibits resting lower oesophageal sphincter tone in a live animal model. ${ }^{4}$ This property was subsequently shown to be useful in the treatment of achalasia, a condition characterised by the failure of the lower oesophageal sphincter to relax. ${ }^{6}{ }^{7}$ Since then, local injection of botulinum toxin has been used in an attempt to lower SO pressures in patients with sphincter of Oddi dysfunction, characterised by a high basal SO pressure. ${ }^{910}$

The rationale behind the use of botulinum toxin in this condition is based on the assumption that net smooth muscle tone in the sphincter is determined by a balance between two opposing sets of nerve influences: an excitatory limb (acetylcholine, substance P, and others) and an inhibitory limb (vasoactive intestinal polypeptide, nitric oxide, and other neurotransmitters). ${ }^{14-17}$ The muscle in the sphincter of Oddi is richly innervated by cholinergic fibres. ${ }^{18}{ }^{19}$ Acetylcholine is released by exocytosis from vesicles of cholinergic nerve endings and binds to muscarinic receptors on the smooth muscle cells, resulting in muscle contractions. This muscarinic effect of acetylcholine is blocked by atropine at the receptor level. Thus as expected, atropine reduces smooth muscle tone in the sphincter of Oddi, ${ }^{20}{ }^{21}$ while cholinergic stimulation increases it. ${ }^{22}$ In contrast to atropine, botulinum toxin exerts its "anticholinergic" effect on striated muscle not by receptor antagonism but by inhibiting the release of acetylcholine from nerve endings. The effects of botulinum toxin therefore are expected to differ in important ways from those of atropine. We attempted to study these in a porcine model. The pig was chosen for these studies because the physiological nature of pig SO seems to be similar to that in man. ${ }^{23}$ Furthemore, we have previously shown that the peptidergic innervation of pig SO is very similar to that of human SO. ${ }^{24} 25$

Our studies in live animals showed a significant reduction in basal SO pressure after botulinum toxin injection directly into the SO. Our experiments have therefore shown that net cholinergic impulses play a dominant role in the maintenance of basal SO tone in vivo. This has been an area of controversy in previous reports with conflicting results reported after vagotomy, ${ }^{26-28}$ as well as in response to atropine and other antimuscarinic agents. ${ }^{29-35}$

Exogenous acetylcholine induced marked contractions in all SO rings. The acetylcholine induced contractions were totally inhibited by atropine but were unaffected by botulinum toxin. This proves that botulinum toxin has no postsynaptic anticholinergic effects such as blockade of muscarinic receptors or binding of acetylcholine. Electrical field stimulation also induced contractions in SO rings that could be inhibited almost totally by atropine, suggesting that they were mediated by acetylcholine. The effects of botulinum toxin were similar to atropine in this preparation. In our model, the replacement of all $\mathrm{NaCl}$ in the medium with $\mathrm{KCl}$ induced contractions in all SO rings, and these contractions were not significantly affected by either atropine or botulinum toxin. This implies that the previously noted effect of botulinum toxin on stimulated smooth muscle contraction is not a result of a non-specific toxic inhibition. Since we have shown that botulinum toxin has no postsynaptic anticholinergic effect, the toxin must therefore act by interfering with the release of endogenous acetylcholine.

In conclusion, botulinum toxin inhibits pig SO smooth muscle contractions by a presynaptic cholinergic mechanism, most likely similar to that described in skeletal muscle. In addition to its therapeutic potential, botulinum toxin may represent a powerful physiological tool to study the intricate workings of the enteric nervous system.

1 Simpson LL. The origin, structure, and pharmacological activity of botulinum toxin. Pharmacol Rev 1981;33:155-88. Blasi J, Chapman ER, Link E, et al. Botulinum neurotoxin A selectively cleaves the synaptic protein SNAP-25. Nature 1993;365:160-3.

3 Jankovic J, Brin MF. Therapeutic uses of botulinum toxin. N Engl fै Med 1991;324:1186-94

4 Pasricha PJ, Ravich WJ, Kalloo AN. Effects of intrasphincteric botulinum toxin on the lower esophageal sphincter in piglets. Gastroenterology 1993;105:1045-9.

5 Pasricha PJ, Kalloo AN. Botulinum toxin for the treatment of gastrointestinal smooth muscle disorders. In: Jankovic J, Hallett M, eds. Therapy with botulinum toxin. New York: Marcel Dekker, 1994.

6 Pasricha PJ, Ravich WJ, Kalloo AN. Botulinum toxin for achalasia. Lancet 1993;341:244-5.

7 Pasricha PJ, Ravich WJ, Hendrix TR, et al. Treatment of achalasia with intrasphincteric injection of botulinum toxin: A pilot trial. Ann Intern Med 1994;121:590-1.

8 Gul D, Cassetta E, Anastasio G, et al. Botulinum toxin for Gul D, Cassetta E, Anastasio G, et al. Botulinum

chronic anal fissure. Lancet 1994;344:1127-8.
9 Pasricha PJ, Miskovsky EP, Kalloo AN. Intrasphincteric injection of botulinum toxin for suspected sphincter of injection of botulinum toxin for suspect
Oddi dysfunction. Gut 1994;35:1319-21.

10 Pasricha PJ, Sostre S, Kalloo AN. Endoscopic injection of botulinum toxin for patients with suspected sphincter of Oddi dysfunction: results of a pilot trial [abstract]. Gastrointest Endosc 1994;40:421.

11 Dickson EC, Shevky R. Botulism, studies on the manner in which the toxin of Clostridium botulinum acts upon the body. I. The effect upon the autonomic nervous system. $\mathcal{F}$ Exp Med 1923;37:711-31.

12 Bigalke H, Habermann E. Blockade of tetanus and botulinum A toxin of postganglionic cholinergic nerve endings in the myenteric plexus. Naunyn Schmiedebergs Arch Pharmacol 1980;312:255-63.

13 Paul ML, Cook MA. Lack of effect of botulinum toxin on nonadrenergic, noncholinergic inhibitory responses of the guinea-pig fundus in vitro. Can $f$ Physiol Pharmacol 1980;58:88-92.

14 Toouli J, Baker RE. Innervation of the sphincter of Oddi: physiology and considerations of pharmacological intervention in biliary dyskinesia. Pharmacol Ther 1991;49:26981

15 Becker JM, Parodi JE. Basic control mechanisms of sphincter of Oddi motor function. Gastrointest Endosc Clin North Am 1993;3:41-66.

16 Makhlouf GM. Smooth muscle of the gut. In: Yamada T, ed. Textbook of gastroenterology. 1st edn. Philadelphia: JB Lippincott Co., 1991:60.

17 Sand J, Arvola P, Jäntti V, et al. The inhibitory role of nitric oxide in the control of porcine and human sphincter of Oddi activity. Gut 1997;41:375-80.

18 Kyösola K. Cholinesterase histochemistry of the innervation of the smooth muscle sphincters around the terminal intramural parts of the ductus choledochus in the cat and dog.
montrat Acta Physiol Scand 1974;90:278-80.

19 Cai W, Gabella G. Innervation of the gall-bladder and biliary pathways in the guinea-pig. $\mathcal{F}$ Anat 1983;136:97-109. 
20 Helm JF, Venu RP, Geenen JE, et al. Effects of morphine on the human sphincter of Oddi. Gut 1988;29:1402-7.

21 Thune BA, Baker RA, Saccone GTP, et al. Pethidine and morphine have different actions on human sphincter of Oddi motility. Br F Surg 1990;77:992-5.

22 Toouli J, Dodds WJ, Honda R, et al. Motor function of the opossum sphincter of Oddi. F Clin Invest 1983;71:208-20.

23 Pasricha PJ, Tietjen TG, Kalloo AN. Endoscopic biliary manometry in swine: a unique model for training and research. Endoscopy 1995;27:70-2.

24 Sand J, Tainio H, Nordback I. Neuropeptides in pig sphincter of Oddi, bile duct, gallbladder, and duodenum. Dig Dis Sci 1993;38:694-700.

25 Sand J, Tainio H, Nordback I. Peptidergic innervation of human sphincter of Oddi. Dig Dis Sci 1994;39:293-300.

26 Pitt HA, Doty JE, Roslyn JJ, et al. The role of altered extrahepatic biliary function in the pathogenesis of gallstones hepatic biliary function in the pathogen

27 Tansy MF, Innes DL, Martin JS, et al. An evaluation of the neural influences on the SO in the dog. Am 7 Dig Dis 1974; 19:423-37.

28 Takahashi I, Dodds WJ, Hogan WJ, et al. Vagotomy and biliary tract motility in the opossum. Dig Dis Sci $1988 ; 33$ : $481-9$
29 Allescher HD, Neuhaus H, Hagemuller F, et al. Effect of N-butylscopolamine on sphincter of Oddi motility in patients during routine ERCP-a manometric study. Endoscopy 1990;22:160-3.

30 DiSomma C, Reboa G, Patrone MG, et al. Effects of pinaverium bromide on Oddi's sphincter. Clin Ther 1986;9: $119-22$

31 Garrigues V, Ponce J, Pertejo V, et al. Effects of atropine and pirenzipine on sphincter of Oddi motility. A manometric study. F Hepatol 1986;3:247-50.

32 Kobayashi K, Mitani E, Tatsumi S, et al. Studies on papillary function and effect of prifinium bromide and other antispasmodics on motility of the papillary region (sphincter of Oddi) in humans. Clin Ther 1985;7:154-63.

33 Lamazza A, Tofi A, Bolognese A, et al. Effects of pinaverium bromide in the premedication of endoscopic retrograde cholangio-pancreatography and on motor activity in the sphincter of Oddi. Curr Med Res Opin 1986;10:280-4.

34 Meshkinpour H, Mollot M, Eckerling GB, et al. Bile duct dyskinesia. A clinical and manometric study. Gastroenterology 1984;87:759-62.

35 Staritz M. Pharmacology of the sphincter of Oddi. Endoscopy 1988;20(suppl 1):171-4. 